\title{
SINERGIA
}

REVISTA DO INSTITUTO DE CIÊNCIAS ECONÔMICAS, ADMINISTRATIVAS E CONTÁBEIS (ICEAC)

\section{PRODUÇÃO CIENTÍFICA EM ADMINISTRAÇÃO: UM ESTUDO BIBLIOMÉTRICO À LUZ DO SEMINÁRIOS EM ADMINISTRAÇÃO DE 2010 A 2019}

MATHEUS MORAIS BRUNO

HENRIQUE CÉSAR MELO RIBEIRO*

\begin{abstract}
RESUMO
Este estudo teve por objetivo investigar o perfil e as características da produção científica em Administração dos artigos publicados nos anais do evento SemeAd de 2010 a 2019. Metodologicamente, utilizaram-se as técnicas bibliométricas, tendo como universo de pesquisa os anais publicados no SemeAd em todas as áreas temáticas, predominando, assim, a abordagem quantitativa. Os indicadores bibliométricos mensurados foram: produtividade, autores, instituições, temas e palavras-chaves. Dessa forma, evidenciou-se um total de 6.909 artigos, 19.938 autores, 569 instituições de ensino e demais organizações, 34 áreas temáticas e 190 temas. O autor e a instituição que mais publicaram no evento, respectivamente, foram Nelson Hein e a Universidade de São Paulo (USP). Os temas mais pesquisados pertencem às áreas temáticas de Administração Pública, Empreendedorismo e Casos de ensino. Conclui-se, a partir dos resultados desta pesquisa, a importância do SemeAd para a difusão, disseminação e socialização da produção científica em Administração, além de expor os temas atuais mais pesquisados para fornecer um panorama para futuras pesquisas na literatura científica brasileira da área.
\end{abstract}

Palavras-chave: Produção científica. Administração. SemeAd.

\section{ABSTRACT}

This study aimed to investigate the profile and characteristics of scientific production in Administration of articles published in the SemeAd proceedings from 2010 to 2019. Methodologically, bibliometric techniques were used, having as research universe the annals published in SemeAd in all thematic areas, predominating thus the quantitative approach. The bibliometric indicators measured were: productivity, authors, institutions, themes and keywords. In this way, a total of 6,909 articles, 19,938 authors, 569 educational institutions and other organizations, 34 thematic areas and 190 themes were highlighted. The author and the institution that most published in the event respectively were Nelson Hein and the University of São Paulo (USP). The most researched topics belong to the thematic areas of Public Administration, Entrepreneurship and Teaching cases. It is concluded from the results of this research the importance of SemeAd for the diffusion, dissemination and socialization of scientific production in Administration, in addition to exposing and contributing with the most researched current themes to provide an overview for future research in the Brazilian scientific literature in the área.

Keywords: Scientific production. Administration. SemeAd.

Recebido em: 21-09-2020 Aceito em: 15-01-2021

\section{INTRODUÇÃO}

A produção científica em Administração incrementa-se ao decorrer dos anos, o que gera uma larga quantidade de informações provenientes destas pesquisas (MIRANDA; CARVALHO; RAMOS, 2016). Nesse contexto, Lazzarini (2017), ao discorrer sobre o impacto da pesquisa em Administração, desperta a relevância nos resultados que a pesquisa, inevitavelmente, deve apresentar. Pressupõe-se que deve haver um direcionamento de novas pesquisas por meio de informações sobre a produção científica.

Dessa forma, a análise da produção científica é uma atividade que permite aos pesquisadores observarem a trajetória da pesquisa relacionada a uma determinada área do conhecimento, mediante a mensuração de variáveis quantitativas (RIBEIRO; RIBEIRO, 2019). O estudo bibliométrico surge, então, como uma técnica para a realização dessa análise (LÖBLER et al., 2019), pois trata-se de "uma área da Ciência da Informação que tem como objetivo analisar a produção científica" (MEDEIROS; VITORIANO, 2015, p. 492), por meio da exploração de dados (MUGNAINI, 2003).

\footnotetext{
Graduando em Administração pela Universidade Federal do Delta do Parnaíba, Campus Ministro Reis Velloso.

"* Pós-Doutor em Administração (UNIFOR). Doutor em Administração (UNINOVE). Doutorando em Contabilidade (UnB). Professor Adjunto da Universidade Federal do Delta do Parnaíba, Campus Ministro Reis Velloso. E-mail: hcmribeiro@gmail.com
} 
No campo da Administração, não ocorre de forma distinta. O estudo bibliométrico é relevante para o desenvolvimento do conhecimento de maneira direcionada (D'ABREU; RITTA; BRAUER, 2020). Os principais meios de divulgação das pesquisas em Administração são as revistas científicas e os anais de eventos científicos. Os eventos destacam-se por serem um meio de comunicação científica informal, que promove maior contato entre pesquisadores e permite discussões e debates sobre temas continuamente incrementados pelas pesquisas (BOHN, 2003; BARKI; BOTELHO; PARENTE, 2013; HAYASHI; GUIMARÃES, 2016).

Dentre os eventos nacionais, o evento Seminários em Administração da FEA-USP - SemeAd é um importante evento científico internacional, que reúne estudos científicos nacionais e estrangeiros e que ocorre, anualmente, na Universidade de São Paulo, por meio do Programas de Pós-Graduação em Administração PPGAs (OLIVEIRA et al., 2018). Fundado em 1996, contempla várias áreas da Administração e é considerado um dos mais importantes eventos científicos em Administração (CASSUNDÉ et al., 2017; SEMEAD, 2020), por proporcionar uma base de dados relevante para a área (CORRÊA; VALE; PINTO, 2018), sendo, com isso, o segundo evento de importância no Brasil, só atrás do Encontro da Associação Nacional de Pós-Graduação e Pesquisa em Administração - EnANPAD (DIEHL et al., 2010; DINIZ et al., 2017; SOARES; PICOLLI; CASAGRANDE, 2018).

Por meio de uma pesquisa com as palavras-chaves "bibliometria" e "semead" no website Google Scholar (LÖBLER et al., 2019), obtiveram-se 1.120 resultados, não sendo possível identificar estudos bibliométricos que abrangessem todo o evento, somente sobre áreas temáticas em específico, como, por exemplo, as pesquisas dos autores: Oliveira et al. (2018) (que enfocou sobre Marketing), Medeiros e Medeiros (2015) (que enfatizou Finanças comportamentais), Oliveira e Gomes (2010) (que investigou Globalização e Internacionalização).

Diante do exposto, constatando que não foi localizado nenhum estudo que investigasse a produção científica do SemeAd de maneira plena e em todas as suas áreas temáticas de uma só vez, surge a questão de pesquisa que norteará este estudo: qual o perfil e as características da produção científica em Administração dos artigos publicados nos anais do evento SemeAd de 2010 a 2019 ? Para ajudar a responder à referida questão de pesquisa, versa-se o objetivo do estudo: investigar o perfil e as características da produção científica em Administração dos artigos publicados nos anais do evento SemeAd de 2010 a 2019.

Justifica-se a temporalidade dos últimos dez anos em virtude de a mesma apresentar o panorama atual das publicações. Releva-se adentrar durante o período de 2010 a 2019, por considerar que esta época apresentou o pico de produção científica do SemeAd em seus 23 anos de vida (1996 a 2019) (SEMEAD, 2020). Em relação aos procedimentos metodológicos, foi uma pesquisa com predomínio quantitativo, utilizando-se das técnicas de análise bibliométrica (RIBEIRO, 2017; LÖBLER et al., 2019), por meio de seus indicadores científicos de produção acadêmica (CARVALHO; SUGANO, 2016). Os artigos publicados, nos anais, foram acessados por meio do site SemeAd. As informações dos artigos foram registradas, calculadas, tabuladas e analisadas por meio do software Microsoft $\Theta^{\circledR}$ Office Excel (LÖBLER et al., 2019).

O presente estudo almeja contribuir apontando os temas mais pesquisados (RIBEIRO et al., 2016), os autores e as instituições que mais publicaram (FAVARETTO; FRANCISCO, 2017) e as palavras-chave mais espessas (GARCIA; GATTAZ; GATTAZ, 2019), a fim de contribuir para dilatar e reforçar o entendimento e a compreensão do estado da arte, da produção científica em Administração, sob a óptica do SemeAd. E, também, a referida pesquisa possibilitará, por meio de uma visão macro, o perfil e as características da produção científica de um dos principais eventos da área no Brasil, o SemeAd (CASSUNDÉ et al., 2017; CORRÊA; VALE; PINTO, 2018; SOARES; PICOLLI; CASAGRANDE, 2018), com contribuições para o seu aperfeiçoamento e fomento, servindo como agenda de pesquisa e possível guia para consulta de estudos similares a este, com o foco neste campo específico do saber científico.

\section{REFERENCIAL TEÓRICO}

A referida seção abordou os assuntos: produção científica e bibliometria.

\subsection{Produção científica}

A pesquisa científica é a obtenção de conhecimento (SOUZA, 2018), e este conhecimento obtido necessita ser comunicado e publicado para agregar valor científico e relevância (RIBEIRO, 2017). Deve-se ter o cuidado em como transmitir o conhecimento ao público-alvo. A linguagem deve ser de fácil compreensão quando se procura realizar a difusão do conhecimento, ou deve ser mais direcionada quando o objetivo é disseminar a um público seleto (CARIBÉ, 2015). Assim, evidencia-se que os eventos científicos são meios de comunicação do conhecimento científico, em que prevalece o contato informal e a difusão oral do conhecimento, permitindo maior troca de experiências entre pesquisadores e o debate de temas atuais e relevantes (RIBEIRO, 2019). 
Após pesquisa realizada, conseguiu-se localizar alguns estudos nacionais, em estado da arte, que versam sobre a produção acadêmica de eventos científicos, com ênfase análoga ao que esta pesquisa se propõe a realizar enfocando a área de Administração. As pesquisas expostas a seguir, além de vislumbrarem o campo do saber Administração, também contemplarão áreas afins.

Guimarâes et al. (2018) discutiram o papel da Associação Nacional de Pós-Graduação e Pesquisa em Administração (ANPAD) nas atividades de publicação científica e de regulação da comunidade científica brasileira de Administração. De maneira geral, os autores enfatizam que a relevância de um artigo pode ser associada ao nível em que a publicação impacta e contribui para o conhecimento existente e/ou a prática administrativa. E dentre os desafios a serem superados para melhorar o grau de relevância da publicação científica brasileira em Administração, o primeiro diz respeito à qualidade intrínseca dessa publicação.

Löbler et al. (2019) investigaram a produção de estudos bibliométricos publicados nos anais de todos os eventos da Associação Nacional de Pós-Graduação e Pesquisa em Administração (AnPAD), no período compreendido entre 2003 e 2019. Os acadêmicos observaram que os artigos são escritos, na maioria das vezes, por dois ou três autores. E as instituições mais profícuas foram: UNINOVE, USP e UNB. Ainda, os resultados evidenciaram as ferramentas computacionais mais usadas para mensuração dos indicadores bibliométricos: Microsoft $\circledast$ Office Excel, SPSS, UCINET® e BibExcel.

Ribeiro e Ribeiro (2019) analisaram o perfil, as características e o comportamento da produção científica divulgada nos estudos publicados no Congresso Anpcont, no período de 2007 a 2016. Os principais resultados observados pelos autores foram: Beuren, Frezatti, Teixeira, Espejo, Macedo, Rodrigues, Miranda, Cornachione Junior, Almeida e Sarlo Neto - autores que se destacaram e que ficaram evidentes na proficuidade das publicações. No que tange às instituições, versam-se: USP, UFMG, UFPB e a FURB, que ficaram em realce na produção de artigos. Em relação aos temas, ficaram em evidência: governança corporativa, gestão de custos, disclosure, contabilidade gerencial, investimento, processo orçamentário, gerenciamento de resultados, informação contábil, contabilidade internacional e gestão pública.

Observando os estudos dos autores desta seção, estes trazem à baila, de maneira respectiva, o panorama do desenvolvimento científico da área de administração e afins, por meio da investigação da produção científica de importantes congressos científicos internacionais. Dessa forma, é salutar afirmar que a produção científica é importante por ser responsável pela disseminação e socialização do conhecimento científico, alicerçando, apoiando e norteando o desenvolvimento da literatura científica do campo do saber em investigação, e, a posteriori, contribuindo para o alargamento, robustez, maturação e legitimação da ciência no país (SILVA et al., 2019). E as técnicas bibliométricas são responsáveis por mensurar a produção científica, focando-se, portanto, em retratar o conhecimento científico divulgado (SANTOS; NETTO; WANG, 2017).

\subsection{Bibliometria}

A bibliometria surge por volta do início do século $X X$, sendo, inicialmente, conhecida como bibliográfia estatística (PRITCHARD, 1969; MEDEIROS; VITORIANO, 2015). E em outras ciências, como Psicometria na Psicologia e Econometria na Economia (ALVARADO; TOUTAIN, 2007). O estudo bibliométrico utiliza da estatística para "medir índices de produção e disseminação do conhecimento, acompanhar o desenvolvimento de diversas áreas científicas e os padrões de autoria, publicação e uso dos resultados de investigação" (LOPES et al., 2012, p. 2).

A bibliometria é alicerçada por três Leis que orientam estes estudos: Lei de Bradford, Lei de Lotka e Lei de Zipf (CHUEKE; AMATUCCI, 2015). A Lei de Bradford trata da produtividade dos periódicos científicos. Diz respeito que a produtividade sobre um determinado assunto é concentrada em grupos com poucos periódicos, e essa produtividade vai diluindo conforme aumenta a quantidade de revistas científicas (LOUSADA et al., 2012). A Lei de Lotka aborda a produtividade dos autores. Desenvolve que a produtividade em uma área do conhecimento estará concentrada em poucos autores e muitos pesquisadores publicaram pouco (ARAÚJO, 2006). E, por fim, a Lei de Zipf refere-se a respeito da frequência de utilização de palavras. Em suma, diz que uma palavra será utilizada em maior frequência, resultando em uma menor variação de um sentido ou significado (ARAÚJO, 2006).

Cabe enfatizar, também, a Lei de Price, que é um desenvolvimento da Lei de Lotka, e que entende que menos de $10 \%$ dos autores, de uma determinada área do saber, produzem aproximadamente $1 / 3$ da informação e conhecimento científico desta área (TEIXEIRA; IWAMOTO; MEDEIROS, 2013), sendo assim, estes pesquisadores considerados a elite deste campo do conhecimento (PESSOA ARAÚJO et al., 2017).

As duas primeiras Leis Bradford e Lotka encaminham a um entendimento sob a ótica do Efeito Mateus, ou seja, muitos têm pouco e poucos têm muito no que tange aos pesquisadores, instituições e ou periódicos (ROSSONI, 2018). Os autores Cintra, Furnival e Milanez (2017) corroboram e complementam ao afirmarem que: 
"A ideia deste efeito está centrada no fato de que cientistas que já possuem uma reputação considerável tendem a receber mais recompensas que seus colegas, seja através de maiores ganhos em visibilidade e na facilidade de obtenção de recursos às suas pesquisas, seja na conquista de prêmios científicos, ou ainda por meio de um maior número de citações aos seus artigos" (CINTRA; FURNIVAL; MILANEZ, 2017).

Em suma, a pesquisa bibliométrica pode ser compreendida como um instrumento de avaliação da pesquisa por meio da abordagem quantitativa. Portanto, os estudos bibliométricos são relevantes para a continuidade do ciclo do conhecimento: ideia/problema, pesquisa e comunicação do resultado (RIBEIRO; CORRÊA, 2014). Tal fato pode ser comprovado mediante estudos bibliométricos que versam sobre diferentes áreas do conhecimento e ou temas científicos como: Administração (FRANCISCO, 2011; RIBEIRO et al., 2016; FAVARETTO; FRANCISCO, 2017; IMASATO; PERLIN; BORENSTEIN, 2017), Contabilidade (LEITE FILHO, 2008), Ensino Superior (MORAES; AMBONI; KALNIN, 2017), Finanças (LEAL; ALMEIDA; BORTOLON, 2013), Governança corporativa (RIBEIRO et al., 2012), Turismo (CARMONA; COSTA; RIBEIRO, 2014), Visão Baseada em Recursos (RIBEIRO et al., 2012), legitimando a importância do estudo bibliométrico para o melhor entendimento e compreensão da ciência.

\section{PROCEDIMENTOS METODOLÓGICOS}

O objetivo deste estudo foi investigar o perfil e as características da produção científica em Administração dos artigos publicados nos anais do evento SemeAd de 2010 a 2019. Para se conseguir alcançar o objetivo proposto, esta pesquisa estruturou-se com o predomínio da abordagem quantitativa, utilizando-se das técnicas bibliométricas. O universo do estudo foi os artigos divulgados no site do SemeAd, porém a amostra compreendeu os artigos publicados nos anais do referido evento do período de 2010 a 2019 de todas as áreas temáticas.

Assim, reforça-se que a pesquisa quantitativa foi o método adequado a esta pesquisa, por proporcionar investigar o perfil e as características da produção acadêmica do SemeAd por meio da quantificação e análise estatística dos dados coletados (VENTURINI; CARRARO, 2020), divergente da pesquisa qualitativa, que objetiva ampliar a compreensão sobre um determinado fenômeno por meio de dados subjetivos associados a indivíduos ou a grupos (FERNANDES et al., 2020).

O SemeAd é um evento realizado pelo Programa de Pós-Graduação em Administração da FEA-USP, de ocorrência anual. É muito importante para a difusão do conhecimento científico em Administração, por reunir várias áreas da Administração. Além disso, é bastante propício para a propagação do saber científicotecnológico em Administração, por reunir uma rede de atores da área de Administração e afins (OLIVEIRA et al., 2018). Em face disso, é visto e considerado como um dos mais importantes congressos científicos da área de Administração do Brasil (CASSUNDÉ et al., 2017).

Os trabalhos submetidos são avaliados por sistema double blind review e, se aprovados, são publicados nos anais e podem concorrer a premiações no evento, além de serem indicados a participarem do fast track entre periódicos nacionais e internacionais (SEMEAD, 2020). A escolha do SemeAd justifica-se pela relevância que o evento tem em nível nacional na área de Administração (CASSUNDÉ et al., 2017). E reforçase a justificativa de se realizar este estudo em decorrência da ausência de pesquisas análogas ao objetivo proposto neste trabalho científico, em outras palavras, não foram encontradas pesquisas que abrangessem todo o evento, concebendo todas as suas áreas temáticas de 2010 a 2019.

Os dados da amostra foram acessados por meio do website do evento http://semead.com.br. Após o download dos estudos, eles foram organizados pelo respectivo ano e área temática. É importante ressaltar a inviabilidade de acesso de alguns artigos, ou seja, alguns papers não foram possíveis de acessar por razões técnicas (falha no website, arquivo incompleto etc.). Mesmo ocorrendo tal fato, foi registrada, na planilha, qualquer informação disponível do estudo para não interferir na contagem total de pesquisas publicadas.

Por ser um estudo longitudinal de uma década (2010 a 2019), as Instituições de Ensino Superior (IES) foram registradas com seus nomes atuais. Tal fato ocorreu em virtude de que, no decorrer do tempo, algumas destas instituições foram mudando o seu nome ou o tipo de organização acadêmica ou tornaram-se extintas. Tal critério foi adotado para garantir a quantificação correta para as instituições. A verificação do nome atual da IES foi feita pelo "Sistema e-MEC", uma base de dados on-line do Ministério da Educação (MINISTÉRIO DA EDUCAÇÃO, 2020).

O download dos artigos ocorreu, paralelamente, com o registro na planilha. Foram registrados respeitando a ordem dos anos e temas conforme disponível no website. Esta fase compreendeu o período de março/2020 a julho/2020. Durante este período, não foi possível acessar 4 (quatro) artigos em 2010, 2011, 2012 e 2015, respectivamente. Considerando a possibilidade de terem sidos publicados em outros eventos ou periódicos, foi realizada uma busca no Google Scholar (LÖBLER et al., 2019) por meio do título do estudo, sendo possível encontrar apenas 2 (dois) artigos, um no ano de 2012 e outro em 2015. 
A análise foi feita no software Microsoft $\Theta$ Office Excel. A escolha do referido software é em decorrência do mesmo ser um dos mais usados para aferição dos indicadores bibliométricos em estudos da área de Administração (LÖBLER et al., 2019). Utilizou-se a função Tabela Dinâmica e foram identificados: total de artigos e total em cada ano, quantidade de autores por publicação em cada ano, os trinta autores que mais publicaram no evento, as vinte IES que mais publicaram no evento, quantidade de vezes publicada, temas mais pesquisados e as palavras-chave mais espessas, visualizada por meio de uma nuvem (FRANCISCO, 2011). Para esta última, sua operacionalização usou o Word Art (RIBEIRO, 2019).

\section{ANÁLISE E DISCUSSÃO DOS RESULTADOS}

Nesta seção, serão apresentados e discutidos os resultados provenientes da análise bibliométrica, com 6.909 dos artigos subdivididos em seis seções: (i) total de artigos; (ii) características de autoria; (iii) autores mais profícuos e demais pesquisadores; (iv) instituições; (v) temas mais abordados; e (vi) nuvem de palavras.

A Figura 1 mostra o total dos 6.909 artigos publicados em 10 anos de divulgação no SemeAd em todas as áreas temáticas.

Figura 1 - Produtividade em dez anos

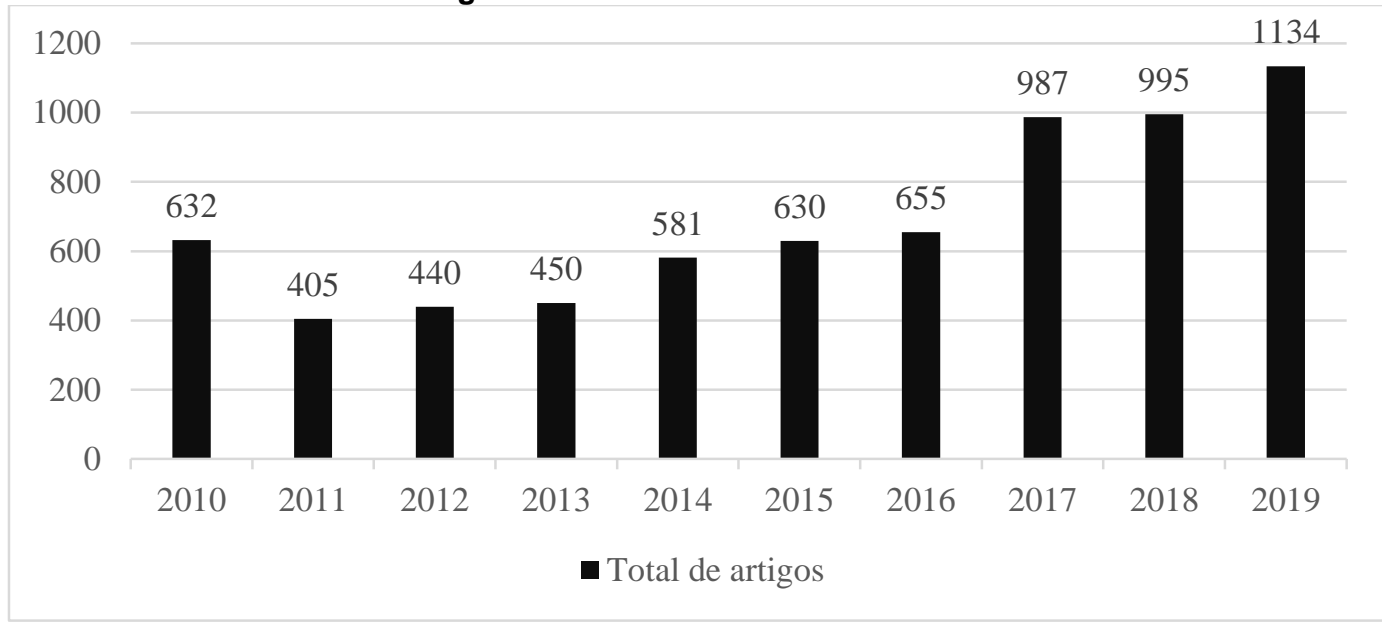

Fonte: Dados da pesquisa

Com 6.909 artigos divulgados, constata-se uma média de 690,9 artigos/ano. Tal média elevou-se, sobretudo, devido aos últimos três eventos ocorridos, 2017, 2018 e 2019, que, somados, representam $45 \%$ do total dos artigos, mostrando a evolução do evento em investigação e seu crescimento como congresso acadêmico, que vem, ano após ano, difundindo, disseminando e socializando o conhecimento científico do campo de Administração (CASSUNDÉ et al., 2017), reforçando, assim, sua importância como uma das principais bases de dados da área (CORRÊA; VALE; PINTO, 2018), alargando e robustecendo, com isso, seu prestígio na comunidade científica em administração (SOARES; PICOLLI; CASAGRANDE, 2018).

A Tabela 1 evidencia as características de autoria dos 19.938 autores identificados neste estudo.

Tabela 1 - Características de autoria

\begin{tabular}{|ccc|ccccccccc|}
\hline Autores por artigo & $\mathbf{2 0 1 0}$ & $\mathbf{2 0 1 1}$ & $\mathbf{2 0 1 2}$ & $\mathbf{2 0 1 3}$ & $\mathbf{2 0 1 4}$ & $\mathbf{2 0 1 5}$ & $\mathbf{2 0 1 6}$ & $\mathbf{2 0 1 7}$ & $\mathbf{2 0 1 8}$ & $\mathbf{2 0 1 9}$ \\
\hline Autoria única & 49 & 27 & 37 & 37 & 65 & 58 & 72 & 83 & 76 & 77 \\
\hline Dois autores & 195 & 88 & 136 & 146 & 184 & 196 & 190 & 313 & 364 & 417 \\
\hline Três autores & 197 & 118 & 121 & 126 & 179 & 192 & 199 & 312 & 306 & 331 \\
\hline Quatro autores & 177 & 171 & 89 & 79 & 98 & 114 & 143 & 174 & 166 & 213 \\
\hline Cinco autores & 13 & 0 & 57 & 62 & 55 & 70 & 51 & 105 & 83 & 96 \\
\hline TOTAL & $\mathbf{6 3 1}$ & $\mathbf{4 0 4}$ & $\mathbf{4 4 0}$ & $\mathbf{4 5 0}$ & $\mathbf{5 8 1}$ & $\mathbf{6 3 0}$ & $\mathbf{6 5 5}$ & $\mathbf{9 8 7}$ & $\mathbf{9 9 5}$ & $\mathbf{1 1 3 4}$ \\
\hline \multicolumn{7}{c}{ Fonte: Dados da pesquisa } \\
\end{tabular}

Observando a Tabela 1, é possível verificar a predominância de artigos com dois, três e quatro autores, nesta ordem. Foram identificados 581 artigos com autoria única, $2.229 \mathrm{com}$ dois autores, $2.081 \mathrm{com}$ três autores, $1.424 \mathrm{com}$ quatro autores e $592 \mathrm{com}$ cinco autores, contudo não foi possível acessar dois artigos para obter o nome dos autores e suas instituições, em 2010 e 2011, estando, somente disponível, o título e a área temática no website, com isso, os totais de 2010 e 2011, na Tabela 1, são, respectivamente, 631 e 404 
artigos, e não 632 e 405 conforme é visualizado na Figura 1, a qual traz o número exato de artigos publicados nos anos de 2010 a 2019.

Percebe-se que, no ano de 2011, não foi identificado nenhum estudo com cinco autores, predominando artigos com quatro autores. Estudos análogos a este, como o dos autores Löbler et al. (2019) e Ribeiro e Ribeiro (2019), corroboram com os achados desta seção, sobretudo, no que concerne à predominância de artigos publicados com dois e três pesquisadores. As pesquisas de Leite Filho (2008), Leal, Almeida e Bortolon (2013), Favaretto e Francisco (2017) e Löbler et al. (2019) confirmam, também, achados similares apesar de enfocarem bases de dados diferentes deste estudo.

Ressalta-se que, em 2016, os estudos com um autor foram impulsionados devido ao Consórcio Doutoral com 21 artigos divulgados, que recebe as propostas de Tese de Doutorando Acadêmico (SemeAd, 2020). O consórcio doutoral, no período analisado, está presente desde 2013, porém, somente em 2016, que os trabalhos estavam nos anais do evento. De maneira geral, o SemeAd é um evento científico que prestigia não apenas os pesquisadores experientes da academia, mas também aqueles que estão iniciando com o consórcio doutoral (BARKI; BOTELHO; PARENTE, 2013).

A Figura 2 vislumbra os 30 autores mais profícuos das 6.909 publicações divulgadas no SemeAd de 2010 a 2019. No período investigado, foi identificado um total de 19.938 autores, dentre esses, o autor que mais publicou foi Nelson Hein, com 27 artigos publicados, seguido por Felipe Mendes Borini e por Paulo Roberto da Cunha, ambos com 21 publicações. Antonio Carlos Aidar Sauaia, Giancarlo Gomes, Márcia Martins Mendes de Luca e Márcia Zampieri Grohmann, todos com 20 divulgações. Rosalia Aldraci Barbosa Lavarda, com 19 artigos. Benny Kramer Costa, Keysa Manuela Cunha de Mascena, Luciana Flores Battistella e Sandra Maria dos Santos, todos com 18 publicações.

Ainda cabe enfocar os estudiosos Alessandra de Avila Montini, llse Maria Beuren, Juliano Nunes Alves, Monica Cavalcanti Sá de Abreu e Sílvio Roberto Stefano com 17 papers divulgados. Os pesquisadores: Antônio de Artur de Souza, Carlos Eduardo Facin Lavarda, Cristina Dai Prá Martens, Darcy Mitiko Mori Hanashiro, Diego de Queiroz Machado, Gilberto Perez, Henrique César Melo Ribeiro, Káren Cristina de Sousa Ribeiro, Luiz Marcelo Antonialli, Marcelo de Rezende Pinto, Roberto Carlos Klann e Sandra Rolim Ensslin todos com 16 estudos publicados; e André Francisco Alcântara Fagundes, com 15 trabalhos evidenciados. Somadas as publicações desses autores, resultam em 532 artigos.

Figura 2 - Autores mais profícuos de 2010 a 2019

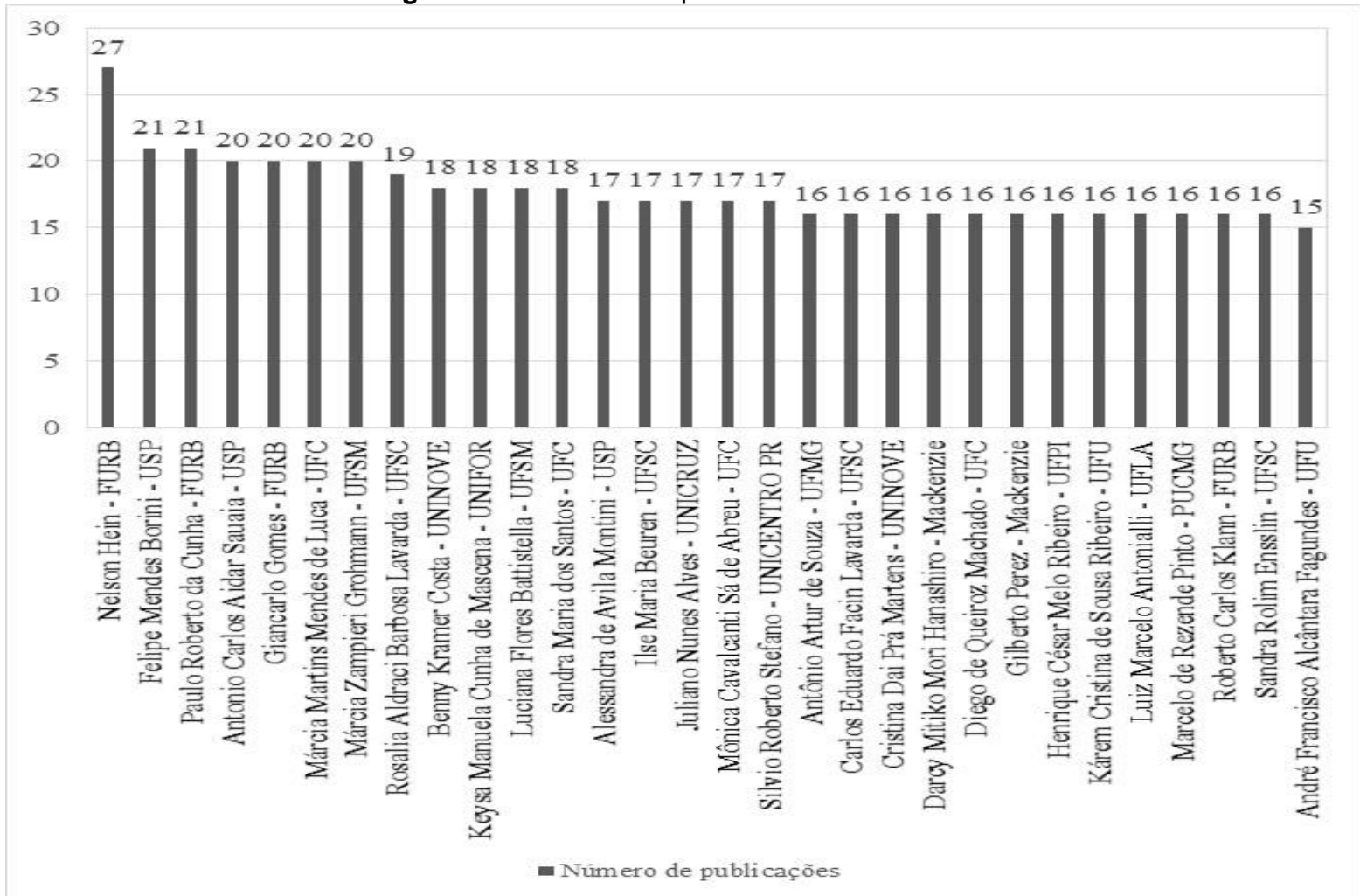

Fonte: Dados da pesquisa

Dessa banda, compreendo o que rege a Lei de Price (TEIXEIRA; IWAMOTO; MEDEIROS, 2013), é coerente afirmar que esses 30 autores mais prolíferos podem ser, para este estudo e sob a óptica das publicações do SemeAd, de 2010 a 2019, em todas as áreas temáticas, considerados a elite (PESSOA 
ARAÚJO et al., 2017) do conhecimento científico do campo do saber Administração. Tal achado permite conceber que tais estudiosos são importantes para a difusão, socialização e disseminação do conhecimento acadêmico nas áreas temáticas que alicerçam o SemeAd, contribuindo, com isso, para saber quais acadêmicos são os mais produtivos e em quais áreas eles mais se destacam (Tabela 2), colaborando para que se possa entender seus respectivos focos de pesquisa, suas possíveis parcerias de estudos, seus direcionadores de criação de valor acadêmico, impactando, diretamente, para o alargamento e para o robustecimento não somente do SemeAd em todas as suas nuances, mas, sobretudo, para a grande área da Administração e afins.

A Tabela 2 complementa a Figura 2 ao contemplar as áreas temáticas predominantes nas publicações dos estudiosos mais profícuos deste estudo.

Tabela 2 - Autores e suas respectivas áreas com maior predomínio de artigos publicados

\begin{tabular}{|c|c|c|c|c|c|}
\hline Autor(a) & Áreas temáticas & Artigos & Autor(a) & Áreas temáticas & Artigos \\
\hline Nelson Hein & Finanças & 10 & $\begin{array}{c}\text { Mônica } \\
\text { Cavalcanti Sá de } \\
\text { Abreu }\end{array}$ & Gestão Socioambiental & 12 \\
\hline $\begin{array}{l}\text { Felipe Mendes } \\
\text { Borini }\end{array}$ & Estratégia em Organizações & 10 & $\begin{array}{l}\text { Silvio Roberto } \\
\text { Stefano }\end{array}$ & Gestão de Pessoas & 9 \\
\hline $\begin{array}{l}\text { Paulo Roberto } \\
\text { da Cunha }\end{array}$ & Finanças & 14 & $\begin{array}{c}\text { Antônio Artur de } \\
\text { Souza }\end{array}$ & Finanças & 11 \\
\hline $\begin{array}{l}\text { Antonio Carlos } \\
\text { Aidar Sauaia }\end{array}$ & Jogos de empresas & 8 & $\begin{array}{l}\text { Carlos Eduardo } \\
\text { Facin Lavarda }\end{array}$ & $\begin{array}{l}\text { Estratégia em } \\
\text { Organizações e } \\
\text { Finanças }\end{array}$ & $\begin{array}{l}7 \\
7\end{array}$ \\
\hline $\begin{array}{c}\text { Giancarlo } \\
\text { Gomes }\end{array}$ & $\begin{array}{l}\text { Estudos Organizacionais e } \\
\text { Gestão da inovação }\end{array}$ & $\begin{array}{l}5 \\
5 \\
\end{array}$ & $\begin{array}{l}\text { Cristina Dai Prá } \\
\text { Martens }\end{array}$ & Empreendedorismo & 9 \\
\hline $\begin{array}{c}\text { Márcia Martins } \\
\text { Mendes de Luca }\end{array}$ & Finanças & 7 & $\begin{array}{c}\text { Darcy Mitiko } \\
\text { Mori Hanashiro }\end{array}$ & Estudos Organizacionais & 14 \\
\hline $\begin{array}{l}\text { Márcia Zampieri } \\
\text { Grohmann }\end{array}$ & Marketing & 6 & $\begin{array}{c}\text { Diego de } \\
\text { Queiroz } \\
\text { Machado } \\
\end{array}$ & $\begin{array}{l}\text { Gestão de Pessoas e } \\
\text { Empreendedorismo }\end{array}$ & $\begin{array}{l}3 \\
3 \\
\end{array}$ \\
\hline $\begin{array}{c}\text { Rosalia Aldraci } \\
\text { Barbosa Lavarda }\end{array}$ & Estratégia em Organizações & 16 & Gilberto Perez & $\begin{array}{l}\text { Tecnologia da } \\
\text { Informação }\end{array}$ & 7 \\
\hline $\begin{array}{c}\text { Benny Kramer } \\
\text { Costa }\end{array}$ & Estratégia em Organizações & 9 & $\begin{array}{l}\text { Henrique César } \\
\text { Melo Ribeiro }\end{array}$ & $\begin{array}{l}\text { Ensino e Pesquisa em } \\
\text { Administração }\end{array}$ & 7 \\
\hline $\begin{array}{l}\text { Keysa Manuela } \\
\text { Cunha de } \\
\text { Mascena }\end{array}$ & Estratégia em Organizações & 14 & $\begin{array}{l}\text { Kárem Cristina } \\
\text { de Sousa } \\
\text { Ribeiro }\end{array}$ & Finanças & 13 \\
\hline $\begin{array}{l}\text { Luciana Flores } \\
\text { Battistella }\end{array}$ & Marketing & 7 & $\begin{array}{c}\text { Luiz Marcelo } \\
\text { Antonialli }\end{array}$ & $\begin{array}{l}\text { Estratégia em } \\
\text { Organizações }\end{array}$ & 4 \\
\hline $\begin{array}{l}\text { Sandra Maria } \\
\text { dos Santos }\end{array}$ & Estudos Organizacionais & 4 & $\begin{array}{c}\text { Marcelo de } \\
\text { Rezende Pinto }\end{array}$ & $\begin{array}{l}\text { Marketing e Marketing e } \\
\text { Comportamento }\end{array}$ & $\begin{array}{l}7 \\
7 \\
\end{array}$ \\
\hline $\begin{array}{l}\text { Alessandra de } \\
\text { Avila Montini }\end{array}$ & Finanças & 11 & $\begin{array}{l}\text { Roberto Carlos } \\
\text { Klann }\end{array}$ & Finanças & 9 \\
\hline $\begin{array}{l}\text { Ilse Maria } \\
\text { Beuren }\end{array}$ & $\begin{array}{c}\text { Estratégia em } \\
\text { Organizações, Finanças e } \\
\text { Governança Corporativa. }\end{array}$ & $\begin{array}{l}3 \\
3 \\
3\end{array}$ & $\begin{array}{l}\text { Sandra Rolim } \\
\text { Ensslim }\end{array}$ & $\begin{array}{l}\text { Estratégia em } \\
\text { Organizações }\end{array}$ & 4 \\
\hline $\begin{array}{l}\text { Juliano Nunes } \\
\text { Alves }\end{array}$ & Administração Geral & 7 & $\begin{array}{l}\text { André Francisco } \\
\text { Alcântara } \\
\text { Fagundes }\end{array}$ & Marketing & 7 \\
\hline
\end{tabular}

Fonte: Dados da pesquisa

De maneira geral, a Tabela 2 traz à baila as áreas temáticas predominantes de publicação dos 30 autores mais profícuos desta pesquisa, contribuindo para entender, compreender e se saber quais nortes, alicerces e enfoques predominantes tais estudiosos gostam de pesquisar. Todavia, é salutar afirmar que estas áreas temáticas respectivas de predomínio de publicação de cada autor, em destaque neste estudo, não significam ser as únicas que esses autores divulgam suas pesquisas, até porque existem acadêmicos, tais como: Giancarlo Gomes, Ilse Maria Beuren, Carlos Eduardo Facin Lavarda, Diego de Queiroz Machado e Marcelo de Rezende Pinto, que ficam em evidencia não somente em uma área temáticas, mas no mínimo em mais uma, mostrando com isso sua propensão em propagar seus respectivos conhecimentos de maneira heterogênea em outros temas acadêmicos que se manifestam em áreas temáticas divergentes. 
Tal fato ajuda e contribui para enriquecer ainda mais a área do saber Administração, mostrando sua diversidade e capacidade de adentrar em ramos do saber que a ramificam, ratificando a horizontalidade, interdisciplinaridade e multidisciplinaridade da área de Administração para a ciência como um todo (FAVARETTO; FRANCISCO, 2017), impactando não somente para a difusão e disseminação das informações e conhecimentos para o evento SemeAd, mas também para toda literatura cientifica nacional da área (GUIMARÂES et al., 2018). Tal fato pode ser aceito em virtude de o SemeAd ser considerado um dos eventos de maior importância e prestígio da área de Administração do Brasil (CASSUNDÉ et al., 2017; CORRÊA; VALE; PINTO, 2018; SOARES; PICOLLI; CASAGRANDE, 2018).

A Tabela 3 complementa a Figura 2 ao evidenciar os demais pesquisadores e suas respectivas quantidades de artigos publicados.

Tabela 3 - Demais pesquisadores e a quantidade de vezes publicadas

\begin{tabular}{ccccc} 
Publicações & Autores & Publicações & Autores & Publicações \\
\hline Uma vez & 6805 & Seis vezes & 137 & Onze vezes \\
\hline Duas vezes & 1571 & Sete vezes & 104 & D3 \\
\hline Três vezes & 705 & Oito vezes & 82 & Doze vezes \\
\hline Quatro vezes & 407 & Nove vezes & 66 & Quatorze vezes \\
\hline Cinco vezes & 223 & Dez vezes & 62 & Quinze vezes \\
\hline
\end{tabular}

Fonte: Dados da pesquisa

Fica em destaque para os 6.805 autores que publicaram somente uma vez e para os 1.571 autores que publicaram duas vezes. Observando a Figura 2 e a Tabela 3, pode-se verificar a ocorrência da Lei de Lotka, que versa sobre a produtividade dos autores (ARAÚJO, 2006) enfocando, também, que poucos publicam muito e muitos publicam pouco (TEIXEIRA; IWAMOTO; MEDEIROS, 2013; RIBEIRO, 2013). Nos estudos de Leite Filho (2008), Leal, Almeida e Bortolon (2013), Ribeiro (2017), Favaretto e Francisco (2017), Löbler et al. (2019) e Ribeiro (2019), de maneira análoga, corroboram com os achados desta seção, confirmando que as publicações em parceria são inerentes ao tema científico pesquisado e, concomitantemente, à área do saber em realce.

De maneira geral, também, a Tabela 3 intensifica a importância da produção em parceria. Isto posto, examina-se que as publicações em parceria são geralmente realizadas entre pesquisadores da mesma instituição que integram um mesmo grupo de pesquisa, ou entre docentes e discentes, de PPGAs ou de cursos de graduação. No que tange às colaborações entre autores de diferentes instituições, estas costumam ser nativas de uma mesma cidade, estado ou região (BOHN, 2003; RIBEIRO et al., 2012; RIBEIRO, 2013; SILVA et al., 2019).

Ainda no tocante às instituições, a Figura 2 deste estudo realça, além dos pesquisadores em destaque, também suas respectivas IES, com as quais estes têm vínculos como docentes/pesquisadores. Destas IES, sete são da região Sudeste: Universidade de São Paulo (USP), Universidade Nove de Julho (Uninove), Universidade Federal de Minas Gerais (UFMG), Universidade Presbiteriana Mackenzie (UPM), Universidade Federal de Uberlândia (UFU), Universidade Federal de Lavras (UFLA) e Pontifícia Universidade Católica (MG); cinco são da região Sul: Universidade Regional de Blumenau (FURB), Universidade Federal de Santa Maria (UFSM), Universidade Federal de Santa Catarina (UFSC), Universidade de Cruz Alta (Unicruz) e Universidade Estadual do Centro Oeste (Unicentro);

Três da região Nordeste: Universidade Federal do Ceará (UFC), Universidade de Fortaleza (Unifor) e Universidade Federal do Piauí (UFPI). Dentre essas, FURB, UFSC e UFC, com quatro aparições com seus respectivos pesquisadores nativos. De maneira geral, tal dado mostra a heterogeneidade em que a produção científica no SemeAd se difundi e se espalha por todo o Brasil, impactando em diferentes tipos de IES, particulares e ou públicas, contribuindo para robustecer e alargar, ainda mais, os temas relacionados à área de Administração e, consequentemente, esta própria área do saber.

A Figura 3 traz à baila as 20 instituições com maior produção científica em dez anos de investigação no SemeAd em todas as suas áreas temáticas.

A USP foi a instituição que mais publicou em dez anos, com 1.097 publicações, representando $15,88 \%$ do total de artigos. A quantidade de artigos publicados pela USP, de certa forma, é explicado em decorrência do SemeAd ser realizado pela USP e organizado pelo seu PPGA (OLIVEIRA et al., 2018). Tal achado é corroborado em pesquisas similares a esta, como, por exemplo, no estudo de Ribeiro (2013), o qual verificou as características da produção científica dos artigos publicados na área temática controladoria e contabilidade gerencial no Congresso USP de Controladoria e Contabilidade no período de 2001 a 2011, constatando a USP como IES mais produtiva nesse estudo. Fato similar ocorrendo, também, nos trabalhos de Oliveira et al. (2018), Medeiros e Medeiros (2015), os quais pesquisaram temas (Marketing e Finanças comportamentais, respectivamente), usando, como base de dados, o SemeAd (CORRÊA; VALE; PINTO, 2018). 
Figura 3 - Vinte instituições que mais publicaram

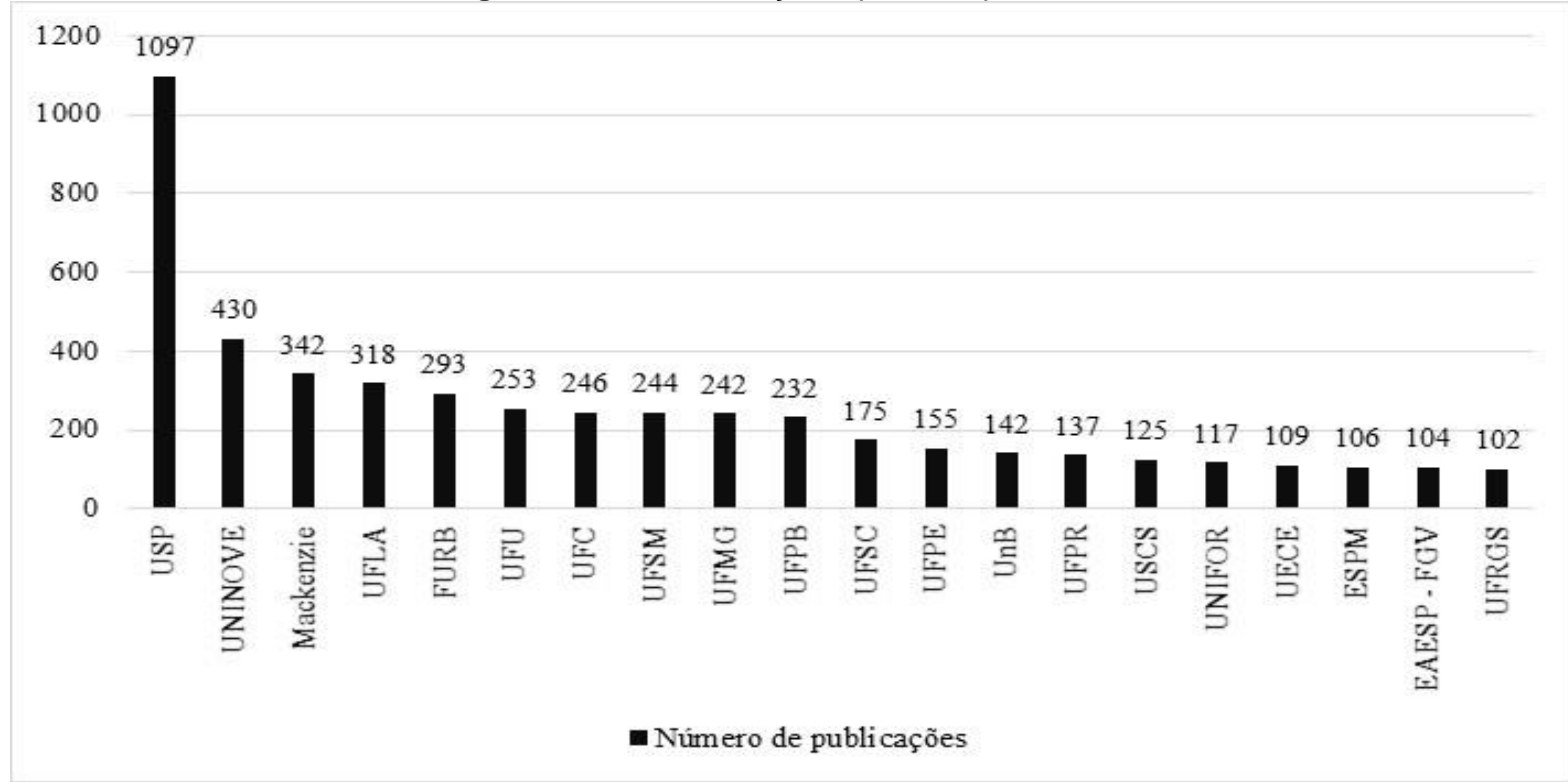

Fonte: Dados da pesquisa

Das 20 IES mais profícuas, nove são da região Sudeste, cinco da região Sul, cinco da região Nordeste, e uma da região centro-oeste. Da mesma forma que a produção se concentra em poucos autores, ocorre, também, com as instituições, pois estas 20 IES concebem $71,91 \%$ do total de artigos publicados. Tal informação vai ao encontro do que foi observado e constatado na Figura 2, evidenciando as IES que ficam em ênfase na produção científica do SemeAd de 2010 a 2019, seja estas: USP, Uninove, UPM, UFLA, FURB, UFU, UFC, UFSM, UFMG (estas ficaram em destaque também na Figura 2). Ainda cabe ressaltar as IES que ficaram em relevo na Figura 3: Universidade Federal da Paraíba (UFPB), Universidade de Brasília (UnB), Universidade Federal do Paraná (UFPR), Universidade Municipal de São Caetano do Sul (USCS), Universidade Estadual do Ceará (UECE), Escola Superior de Propaganda e Marketing (ESPM), Fundação Getúlio Vargas (SP) e Universidade Federal do Rio Grande do Sul (UFRGS).

Em suma, foram identificadas 569 instituições de 2010 a 2019. Deste total, encontram-se os tipos de organizações acadêmicas: universidade, centro universitário, faculdade, centro federal de educação tecnológica e instituto federal de educação, ciência e tecnologia. Foram identificados órgãos públicos federais e estaduais, organizações privadas sem fins lucrativos, IES internacionais e empresas privadas. Tal achado, novamente, vem a corroborar e confirmar a vanguarda que o SemeAd tem para com a difusão, disseminação e socialização do conhecimento acadêmico da área de Administração no Brasil, contribuindo para colocar em emergência temas ainda embrionários na academia ou maturar temáticas emergentes na literatura científica, e ou, legitimar assuntos maduros no contexto científico literário da administração. Também, com grande propensão em prospectar temáticas que se tornarão tópicos quentes no âmbito acadêmico dos PPGAs pelo Brasil.

A Tabela 4 contempla os temas mais abordados nos 6.909 artigos publicados em dez anos de produção científica no SemeAd em todas as suas áreas temáticas. A criação da citada tabela baseou-se no estudo dos autores Ribeiro et al. (2016). 
Tabela 4 - Quinze temas mais pesquisados

\begin{tabular}{|c|c|c|c|}
\hline Área temática & Tema & $\begin{array}{c}\text { № de } \\
\text { publicações }\end{array}$ & Período \\
\hline Administração Pública & $\begin{array}{l}\text { Relação governo - sociedade: transparência, } \\
\text { accountability e participação }\end{array}$ & 185 & $\begin{array}{l}2012- \\
2019\end{array}$ \\
\hline $\begin{array}{c}\text { Estudos } \\
\text { Organizacionais }\end{array}$ & Comportamento organizacional & 152 & $\begin{array}{l}2012- \\
2016, \\
2018- \\
2019\end{array}$ \\
\hline Casos de Ensino & Casos de ensino & 135 & $\begin{array}{l}2012- \\
2019\end{array}$ \\
\hline $\begin{array}{l}\text { Estratégia em } \\
\text { Organizações } \\
\end{array}$ & Processos estratégico nas organizações & 129 & $\begin{array}{l}2012- \\
2019 \\
\end{array}$ \\
\hline Gestão Socioambiental & Estratégia e sustentabilidade & 128 & $\begin{array}{l}2012- \\
2019\end{array}$ \\
\hline Administração Pública & $\begin{array}{l}\text { Promoção da eficiência, otimização de processos e de } \\
\text { recursos públicos }\end{array}$ & 122 & $\begin{array}{l}2013- \\
2019\end{array}$ \\
\hline Administração Pública & $\begin{array}{l}\text { Gestão organizacional: governança, planejamento, } \\
\text { recursos humanos e capacidades }\end{array}$ & 121 & $2016-$ \\
\hline Gestão Socioambiental & Gestão ambiental & 116 & $\begin{array}{l}2012- \\
2019\end{array}$ \\
\hline Gestão de Pessoas & Carreiras e competências & 106 & $\begin{array}{l}2015- \\
2019\end{array}$ \\
\hline $\begin{array}{l}\text { Estratégia em } \\
\text { Organizações }\end{array}$ & Estratégia internacional e globalização & 103 & $\begin{array}{l}2012- \\
2019\end{array}$ \\
\hline Finanças & Contabilidade & 99 & $2015-$ \\
\hline Finanças & Governança, risco e compliance & 92 & $\begin{array}{l}2015- \\
2019\end{array}$ \\
\hline Empreendedorismo & $\begin{array}{l}\text { A figura do empreendedor: perfil, personalidade, } \\
\text { comportamento e competências }\end{array}$ & 90 & $\begin{array}{l}2013- \\
2019\end{array}$ \\
\hline $\begin{array}{l}\text { Estratégia em } \\
\text { Organizações }\end{array}$ & Cluster e redes de negócios & 88 & $\begin{array}{l}2012- \\
2019\end{array}$ \\
\hline Gestão de Pessoas & Gestão de pessoas e equipes & 88 & $\begin{array}{l}2015- \\
2019\end{array}$ \\
\hline Total & & 1754 & \\
\hline
\end{tabular}

Fonte: Dados da pesquisa

Os temas foram introduzidos a partir de 2012 dentro das áreas temáticas. A Tabela 4 revela que o tema Relação governo - sociedade: transparência, accountability e participação da área de Administração Pública foi o mais pesquisado, com 185 publicações, do período de 2012 a 2019. Logo em seguida, surge Comportamento organizacional da área Estudos Organizacionais, com 152 publicações. E, em terceiro, aparece o tema Casos de Ensino na área Casos de Ensino. Na área temática Estratégia em Organizações, surge a temática Processos estratégicos nas organizações com 129 publicações, e o tema Estratégia e sustentabilidade fica em realce na área temática Gestão Socioambiental. De maneira geral, Administração Pública e Estratégia em Organizações foram as áreas temáticas com mais temas presentes na mencionada tabela, cada uma com três temas em relevo. Percebe-se que todos estes temas possuem períodos longos no evento, subentende-se que são temas que ainda são alvos de grande interesse de pesquisas.

De maneira macro, a Tabela 4 contribui para mostrar a riqueza, a horizontalidade e as ramificações que a área do saber Administração contém em suas nuances e em seu bojo teórico, prático, técnico. Elencando, à luz do SemeAd, temáticas diversas e de distintos enfoques, que, de certa forma, também se interagem entre si, alargando e robustecendo a Administração como ciência.

As áreas temáticas que hoje encabeçam, norteiam e embasam o SemeAd: administração Pública, Agribusiness, Empreendedorismo, Ensino e Pesquisa, Estratégia em Organizações, Estudos Organizacionais, Finanças, Gestão da Inovação, Gestão de Pessoas, Gestão Socioambiental, Marketing, Operações, Tecnologia da Informação, Turismo e Hospitalidade e Artigos Aplicados (SEMEAD, 2020), também, ajudam a entender e a compreender a heterogeneidade de temas que contribuem para enriquecer o referido evento no âmbito, não somente nacional, mas quiçá internacional, criando valor científico, fomentando as parcerias entre os pesquisadores, entre grupos de estudos, entre os PPGAs, entre as instituições, e, consequentemente, entre as regiões do Brasil, impactando no crescimento e no prestígio que o referido evento tem para com a ciência, colaborando para legitimar ainda mais a área de Administração no meio acadêmico. 
A Figura 4 visualiza a nuvem de palavras, enfocando primeira palavra-chave de cada estudo.

Figura 4 - Nuvem de palavras

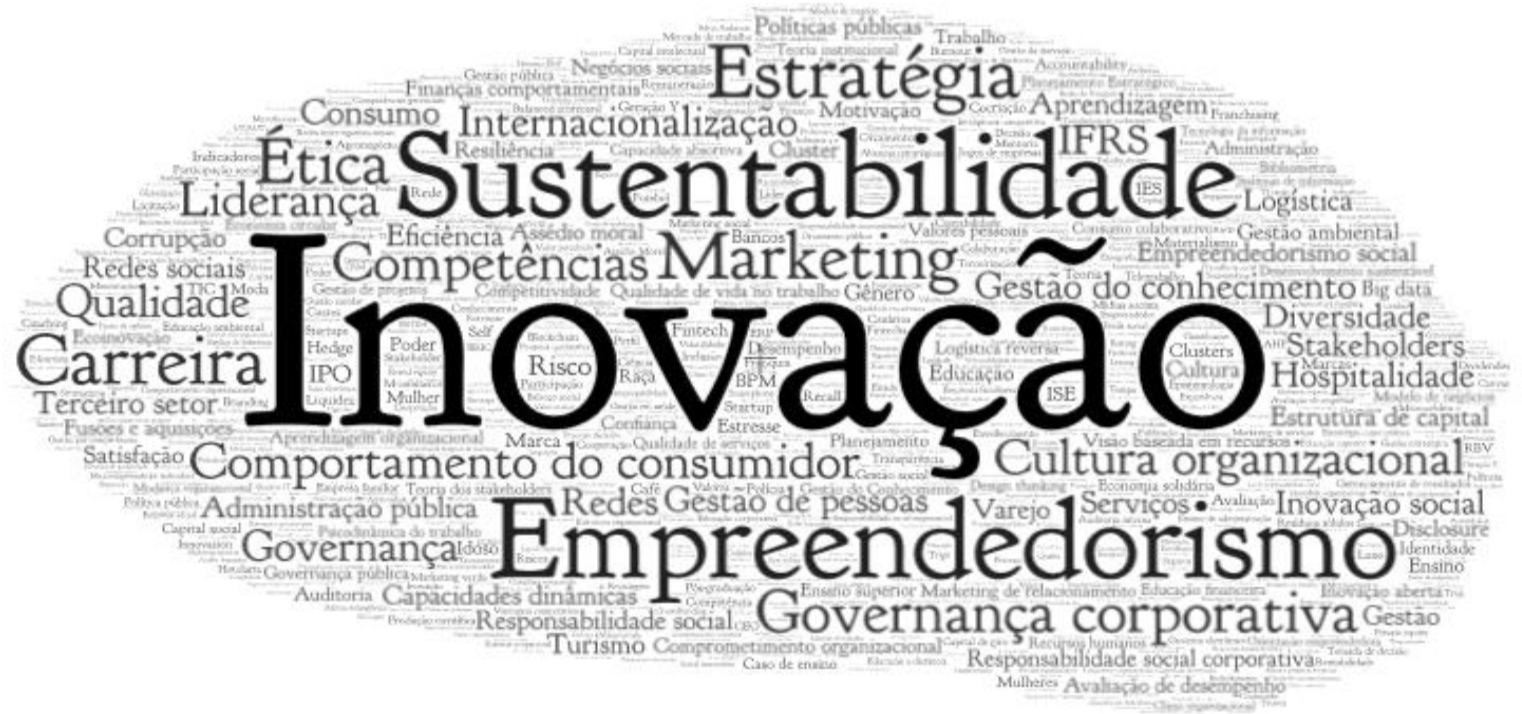

Fonte: Dados da pesquisa

Justifica-se o uso das palavras-chave para a criação da referida nuvem, em virtude de essas facilitarem a recuperação de maneira eficiente do conteúdo de um texto para os leitores (GARCIA; GATTAZ; GATTAZ, 2019). Com isso, tais palavras interagem e relacionam-se com o tema foco de cada estudo (CARVALHO; SUGANO, 2016), e a primeira palavra-chave robustece tal ação e constatação.

As dez palavras que mais se repetiram foram respectivamente: inovação, empreendedorismo, sustentabilidade, governança corporativa, estratégia, marketing, comportamento do consumidor, cultura organizacional, internacionalização e gestão do conhecimento. A partir da Figura 4, versa-se a Lei de Zipf (ARAÚJJ, 2006), constatando poucas variações de uma palavra e os assuntos mais abordados nos estudos (CHUEKE; AMATUCCI, 2015). Informações essas corroboradas, de maneira análoga, na pesquisa de Francisco (2011), Favaretto e Francisco (2017) e Ribeiro (2019).

\section{CONSIDERAÇÕES FINAIS}

Este estudo teve como objetivo investigar o perfil e as características da produção científica em Administração dos artigos publicados nos anais do evento SemeAd de 2010 a 2019. Diante disso, foi realizada uma pesquisa longitudinal por meio de uma análise bibliométrica nos anais do referido evento, trabalhando os indicadores acadêmicos de produção (CARVALHO; SUGANO, 2016), relacionados à produtividade, à autoria, às instituições e a temas (RIBEIRO et al., 2016; FAVARETTO; FRANCISCO, 2017; GARCIA; GATTAZ; GATTAZ, 2019). No período de dez anos, ou seja, de 2010 a 2019, foram publicados, no SemeAd 6.909 artigos, sendo os três últimos anos, 2017, 2018 e 2019, responsáveis por quase a metade do total, cerca de $45 \%$ do montante do total de papers divulgados. Nesse ínterim, predominaram os artigos publicados em parceria, sobretudo, com dois, três e quatro autores, o que equivale em percentuais de $32 \%, 30 \%$ e $21 \%$, concomitantemente.

Foram identificados 19.938 autores, sendo Nelson Hein o autor que mais publicou no período, com 27 publicações. Os trinta autores que mais publicaram somam um total de 532 artigos, representam $7,70 \%$ do total. Dessa maneira, é fato afirmar que esses pesquisadores em realce podem ser considerados a elite da produção científica em Administração em dez anos (2010 a 2019), sob a óptica do SemeAd, de acordo com o que preconiza a Lei de Price (TEIXEIRA; IWAMOTO; MEDEIROS, 2013; PESSOA ARAÚJO et al., 2017).

$\mathrm{Na}$ quantidade de vezes em que um artigo foi publicado, predominou os 6.805 autores que publicaram apenas uma vez, equivalendo a $34,13 \%$ do total de artigos divulgados. Tal fato remete à Lei de Lotka, a qual enfoca a produtividade dos autores ARAÚJO, 2006) e, neste estudo, reitera e reforça, também, o que ocorre em muitas outras pesquisas de calibre semelhante a esta de que muitos publicam pouco, e poucos publicam muito (RIBEIRO, 2017). Tal fato é corroborado pelo Efeito Mateus (ROSSONI, 2018), que incorre na reputação destes pesquisadores que publicam muito, em virtude de mérito (CINTRA; FURNIVAL; MILANEZ, 2017). Das 569 instituições identificadas, a USP foi a que mais publicou, com 1.097 artigos.

Durante o período, o evento teve 34 áreas temáticas e 190 temas. Os três temas mais pesquisados são: relação governo-sociedade: transparência, accountability e participação; comportamento organizacional; 
casos de ensinos. Pertencentes, respectivamente, às áreas Administração Pública, Estudos Organizacionais e Casos de Ensino. Ao analisar as palavras-chave, obtiveram-se as principais palavras como resultado: inovação, empreendedorismo, sustentabilidade, governança corporativa e estratégia. O que é possível observar neste panorama é que as palavras-chave, visualizadas na nuvem deste estudo (Figura 4), se conectam com as áreas temáticas e com os temas mais abordados. Com isso, é possível afirmar que seja intrínseca a conexão existente entre as temáticas evidenciadas e as palavras-chave dos 6.909 estudos publicados. Tal resultado é confirmado, em outras pesquisas (FRANCISCO, 2011; RIBEIRO et al., 2016; FAVARETTO; FRANCISCO, 2017) similares a esta, que enfocaram em realizar, respectivamente, mapeamentos em periódicos importantes da área de Administração.

Por meio desta pesquisa, é possível constatar a importância do SemeAd no contexto da produção científica em Administração (CASSUNDÉ et al., 2017; CORRÊA; VALE; PINTO, 2018), visto a ampla quantidade de áreas temáticas, temas e autores que o SemeAd, em dez anos, difundiu, disseminou e socializou, contribuindo para robustecer e alargar, na literatura científica, o campo do saber Administração. Este estudo também expõe os temas mais pesquisados, todos estes presentes na última edição realizada em 2019.

Dessa banda, realça-se a importância do evento científico SemeAd para a área de Administração no Brasil, não somente mediante seus atores (pesquisadores e suas respectivas IES) que propagam diversos assuntos aderentes à Administração e que os fazem robustecer ainda mais a referida área do saber para a academia, mas também que tais assuntos são publicados e, posteriormente, citados/referenciados por agentes disseminadores e socializados do conhecimento científico, por estudiosos e seus grupos de pesquisa, divulgando seus achados, contribuições e resultados em meios de comunicação, tais como, periódicos nacionais e/ou internacionais, trazendo à baila o nome do SemeAd para o contexto da produção acadêmica brasileira. Ou seja, as revistas científicas, alargando e proporcionando uma maior maturidade e legitimação do mencionado evento científico, não somente no contexto brasileiro, mas também no internacional, fortalecendo, assim, sua importância, relevância e envergadura como evento científico da área de Administração do Brasil.

Em suma, e diante desses resultados, esta pesquisa permitiu uma visão macro da produção científica nos principais eventos da área de Administração no Brasil (CASSUNDÉ et al., 2017; CORRÊA; VALE; PINTO, 2018), como também mostrou o perfil e as características desses estudos ao longo de dez anos de publicação em todas as áreas temáticas, criando valor científico e proporcionando um panorama e um norte aos estudiosos, curiosos, leitores, pesquisadores, docentes, discentes e demais interessados, podendo, assim, agenciar o avanço científico nesse campo do saber (LÖBLER et al., 2019). E, a posteriori, criar novos meios de difundir o conhecimento científico da Administração no Brasil e, quiçá, no mundo, como, por exemplo, novos eventos científicos que podem se ancorar e se nortear pelo SemeAd, e/ou até periódicos científicos que se alicercem pelas áreas temáticas do próprio SemeAd, contribuindo para gerar seus respectivos escopos e focos de pesquisa para a área de Administração e/ou afins, como é o caso do campo do saber da Contabilidade.

O estudo se limitou a adentrar na análise bibliométrica, porém, tanto a questão de pesquisa como também o objetivo do estudo foram, respectivamente, respondidos e alcançados. A seguir, vêm algumas sugestões para estudos futuros: (i) replicar este estudo agora, fazendo uma análise comparativa com um outro evento de igual envergadura, como, por exemplo, o EnANPAD; (ii) realizar uma revisão sistêmica sobre esse artigo; (iii) analisar as redes de colaboração dos atores por meio da sociometria, enfocando as redes de coautoria, redes de cocitação; e (iv) realizar uma revisão teórica sobre os temas abordados neste estudo.

\section{REFERÊNCIAS}

ALVARADO, R. U.; TOUTAIN, L. M. B. B. (org). Para entender a ciência da informação. Salvador: EDUFBA, 185-217 p., 2007.

ARAÚJO, C. A. Bibliometria: evolução histórica e questões atuais. Em Questão, v. 12, n. 1, p. 11-32, 2006.

BARKI, E.; BOTELHO, D.; PARENTE, J. Varejo: desafios e oportunidades em mercados emergentes. RAE, v. 53, n. 6, p. 534-538, 2013.

CARIBÉ, R. de C. do V. Comunicação científica: reflexões sobre o conceito. Informação \& Sociedade, v. 25, n. 3, p. 89104, 2015.

CARMONA, V. C.; COSTA, B. K.; RIBEIRO, H. C. M. Competitividade e turismo: estudo da produção científica internacional. RBTUR, v. 8, n. 2, p. 201-221, 2014

CARVALHO, E. G.; SUGANO, J. Y. 5 anos de trabalho, 10 edições e mais de 100 trabalhos publicados: a identidade da revista Navus. NAVUS, v. 6, n. 1, p. 41-46, 2016.

CASSUNDÉ, F. R. de S. A. et al. [Re]pensando o estágio na formação profissional dos estudantes de administração: um estudo sobre a produção científica brasileira na área. Administração: Ensino e Pesquisa, v. 18, n. 3, p. 594-623, 2017. 
CHUEKE, G. V.; AMATUCCI, M. O que é bibliometria? uma introdução ao Fórum. Internext, v. 10, n. 2, p. 1-5, 2015.

CINTRA, P. R.; FURNIVAL, A. C.; MILANEZ, D. H. O acesso aberto à luz dos Estudos Sociais da Ciência e Tecnologia. Encontros Bibli, v. 22, n. 50, p. 205-222, 2017.

CORRÊA, V. S.; VALE, G. M. V.; PINTO, M. de R. Acoplamento e desacoplamento sociais: pastores como empreendedores. RAE, v. 58, n. 2, p. 188-200, 2018.

D'ABREU, I. M.; RITTA, P. M. A. S.; BRAUER, M. Análise das bibliometrias em administração na base Spell. Revista Vianna Sapiens, v. 11, n. 1, p. 76-96, 2020.

DIEHL, C. A. et al. metodologias em artigos de finanças sobre dividendos nos periódicos brasileiros Qualis/Capes a partir de B2. RPCA, v. 4, n. 2, p. 18-35, 2010.

DINIZ, E. H. et al. Formação, disseminação e colaboração: internacionalização em administração de sistemas de informação. RAC, v. 21, n. 6, p. 811-831, 2017.

FAVARETTO, J. E. R.; FRANCISCO, E. de R. Exploração do acervo da RAE-Revista de Administração de Empresas (de 1961 a 2016) à luz da bibliometria, text mining, rede social e geoanálise. RAE, v. 57, n. 4, p. 365-390, 2017.

FERNANDES, N. P. et al. Quem é o empreendedor? a busca por uma definição do conceito através da produção científica brasileira. RBGI, v. 7, n. 3, p. 26-62, 2020.

FRANCISCO, E. de R. RAE-eletrônica: exploração do acervo à luz da bibliometria, geoanálise e redes sociais. RAE, v. 51, n. 3, p. 280-306, 2011.

GARCIA, D. C. F.; GATTAZ, C. C.; GATTAZ, N. C. A Relevância do título, do resumo e de palavras-chave para a escrita de artigos científicos. RAC, v. 23, n. 3, p. 1-9, 2019.

GUIMARÂES, T. A. et al. A ANPAD e o processo de institucionalização da comunidade científica brasileira de Administração. Cadernos EBAPE.BR, v. 16, p. 523-537, 2018.

HAYASHI, M. C. P. I.; GUIMARÃES, V. A. L. A comunicação da ciência em eventos científicos na visão de pesquisadores. Em Questão, v. 22, n. 3, p. 161-183, 2016.

IMASATO, T.; PERLIN, M. S.; BORENSTEIN, D. Análise do perfil dos acadêmicos e de suas publicações científicas em administração. RAC, v. 21, n. 1, p.62-83, fev. 2017.

LAZZARINI, S. Pesquisa em administração: em busca de impacto social e outros impactos. Revista de Administração de Empresas, v. 57, n. 6, p. 620-625, 2017.

LEAL, R. P. C.; ALMEIDA, V. de S. e; BORTOLON, P. M. Produção científica brasileira em finanças no período $2000-$ 2010. RAE, v. 53, n. 1, p. 46-55, 2013.

LEITE FILHO, G. A. Padrões de produtividade de autores em periódicos e congressos na área de contabilidade no Brasil: um estudo bibliométrico. RAC, v. 12, n. 2, p. 533-554, 2008.

LÖBLER, M. L. et al. Evolução bibliométrica: uma análise dos trabalhos publicados nos eventos da ANPAD. Revista Sociais \& Humanas, v. 32, n. 3, p. 11-31, 2019.

LOPES, S.; COSTA, M. T.; FERNÁNDEZ-LLIMÓS, F.; AMANTE, M. J.; LOPES, P. F. A bibliometria e a avaliação da produção científica: indicadores e ferramentas. Actas dos Congressos Nacionais de Bibliotecários, Arquivistas e Documentalistas, n. 11, p. 1-7, 2012.

LOUSADA, M. et al. Produção científica sobre gestão do conhecimento e gestão da informação no âmbito da Ciência da Informação: Uma aplicação da lei de Bradford. Anales de Documentación, v. 15, n. 2, p. 1-17, 2012.

MEDEIROS, J. M. G. de; VITORIANO, M. A. V. A evolução da bibliometria e sua interdisciplinaridade na produção científica brasileira. RDBCI, v. 13, n. 3, p. 491-503, 2015.

MEDEIROS, N. de C. L. de; MEDEIROS, F. S. B. Produção acadêmica sobre finanças comportamentais: uma análise no SEMEAD. Revista UNIABEU, v. 8, n. 19, p. 158-175, 2015.

MINISTÉRIO DA EDUCAÇÃO. e-MEC. Disponível em: < http://portal.mec.gov.br/e-mec>. Acesso em: abr.2020.

MIRANDA, A. C. C. de; CARVALHO, A. V.; RAMOS, A. S. M. Comunicação científica em administração. Revista Ciências Administrativas, v. 22, n. 2, p. 573-604, 2016.

MORAES, M. C. B.; AMBONI, N.; KALNIN, G. F. Produção acadêmica em avaliação do ensino superior no Brasil. Avaliação, v. 22, n. 3, p. 697-717, 2017.

MUGNAINI, R. A bibliometria na exploração de bases de dados: a importância da lingüística. Transinformação, v. 15, n. 1, p. 45-52, 2003.

OLIVEIRA, L. D. M. de et al. Pesquisa da área do marketing do SEMEAD. Marketing \& Tourism Review, v. 3, n. 3, p. 120, 2018.

OLIVEIRA, R. R.; GOMES, J. S. Globalização e Internacionalização de Empresas nos Seminários em Administração da USP: Estudo Bibliométrico. Anais... Simpósio de Excelência em Gestão e Tecnologia, Resende, 2010.

PESSOA ARAÚJO, U. et al. Trajetória e estado corrente da sociometria brasileira. Revista Hispana para el Análisis de Redes Sociales, v. 28, n. 2, p. 97-128, 2017.

PRITCHARD, A. Statistical bibliography or bibliometrics. JD, v. 25, n. 4, p. 348, 1969 
RIBEIRO, H. C. M. Bibliometria: quinze anos de análise da produção acadêmica em periódicos brasileiros. Biblios, n. 69, p. 1-20, 2017.

RIBEIRO, H. C. M. Bitcoin: análise da produção científica internacional de 2008 a 2017. Sinergia, v. 23, n. 1, p. 81-94, 2019.

RIBEIRO, H. C. M. Contribuição do congresso USP ao estudo da área temática controladoria e contabilidade gerencial: uma bibliometria. RACE, v. 12, n. 2, p. 709-746, 2013.

RIBEIRO, H. C. M. Controladoria e contabilidade gerencial: dez anos de produção científica. Revista Pretexto, v. 20, n. 2, p. 100-121, 2019.

RIBEIRO, H. C. M. et al. 35 anos de publicações acadêmicas da revista de administração da USP. Ambiente, v. 8, n. 1, 2016.

RIBEIRO, H. C. M.; CORRÊA, R. Estado da arte da Revista de Administração Mackenzie: análise da produção científica de 2008 a 2012. GUAL, v. 7, n. 2, p. 152-174, 2014.

RIBEIRO, H. C. M. et al. Visão baseada em recursos: uma análise bibliométrica dos últimos 11 anos. Revista de Ciências da Administração, v. 14, n. 34, p. 39-59, 2012.

RIBEIRO, H. C. M. et al. Governança corporativa: um estudo bibliométrico da produção científica das dissertações e teses brasileiras. CGG, v. 15, n. 3, p. 52, 2012.

RIBEIRO, H. C. M.; RIBEIRO, G. K. M. Análise de dez anos da produção acadêmica divulgada nos estudos científicos publicados no congresso ANPCONT. Revista Ciências Administrativas, v. 25, n. 1, p.1-18, 2019.

ROSSONI, L. Editorial: O Spell reduziu o efeito Mateus na citação de periódicos. Revista Eletrônica de Ciência Administrativa, v. 17, n. 1, p. 1-8, 2018.

SANTOS, G. E. de O.; NETTO, A. P.; WANG, X. Análise de citaçõess de periódicos científicos de turismo no Brasil: subsídios para a estimação de indicadores de impacto. Revista Brasileira de Pesquisa em Turismo, v. 11, n. 1, p. 6188, 2017

SEMINÁRIOS EM ADMINISTRAÇÃO - SEMEAD. Disponível em: < https://semead.com.br/23/>. Acesso em: abr. 2020.

SILVA, L. C. da et al. Perfil dos programas de pós-graduação Stricto Sensu em Gestão do Conhecimento no Brasil e seu panorama da produção científica. Avaliação:, v. 24, n. 1, p. 328-351, 2019.

SOARES, S. V.; PICOLLI, I. R. A.; CASAGRANDE, J. L. Pesquisa bibliográfica, pesquisa bibliométrica, artigo de revisão e ensaio teórico em administração e contabilidade. Administração: Ensino e Pesquisa, v. 19, n. 2, p. 1-19, 2018.

SOUZA, M. Produção científica brasileira. BJIS: RT, v. 12, n. 1, 2018.

TEIXEIRA, M. L. M.; IWAMOTO, H. M.; MEDEIROS, A. L. Estudos bibliométricos (?) em administração: discutindo a transposição de finalidade. RAEP, v. 14, n. 3, p. 423-452, 2013.

VENTURINI, L. D. B.; CARRARO, W. B. W. H. Estágio evolutivo da contabilidade gerencial em organizações contábeis de natureza jurídica EIRELI no Município de Porto Alegre - RS. Revista Capital Científico - Eletrônica, v. 18, n. 2, p. 81-99, 2020. 